Original scientific paper

\title{
SIMULATION STUDY OF IMPACT OF CAPACITY RESERVATION THRESHOLD ON ORDER FULFILMENT
}

\author{
Gong, D. C. ${ }^{* * *} ;$ Chen, P. S. ${ }^{* * * \#} \&$ Wang, S. J. ${ }^{* * *}$ \\ *Department of Industrial and Business Management, Chang Gung University, Guishan Dist., \\ Taoyuan City 333323, Taiwan, ROC \\ ** Division of Supply Chain, Chang Gung Memorial Hospital-Linkou, Guishan Dist., \\ Taoyuan City 333323, Taiwan, ROC \\ *** Department of Industrial and Systems Engineering, Chung Yuan Christian University, \\ Chung Li Dist., Taoyuan City 320314, Taiwan, ROC \\ E-Mail: gongdc@mail.cgu.edu.tw, pinghun@cycu.edu.tw, jaret00043@gmail.com ("Corresp. Author)
}

\begin{abstract}
Given the high prices of machine tools, customers often engage in careful deliberation before placing any orders for machines. The number and size of orders may suddenly change when the demand unexpectedly increases or plummets. This paper proposes the concept of "reservation threshold", which refers to mitigating possible crowding-out by applying advanced capacity for handling potential orders. This threshold also serves as an order entrance control to reduce the number of non-confirmed orders. A simulation model is used to explore the impact of various threshold values on production system profitability. Data abstracted from a representative company are used as a case study. Scenarios for three reservation strategies are examined for negotiation probability distributions. Through numerical experiments, the significance of an appropriate reservation threshold is demonstrated for normal capacity scenarios; the reservation strategy outperforms the no-reservation strategy under conditions of normal and insufficient capacity while the module reservation strategy is the best of the three reservation strategies.
\end{abstract}

(Received in August 2020, accepted in December 2020. This paper was with the authors 1 month for 1 revision.)

Key Words: Capacity Planning, Potential Order, Reservation Threshold, Reservation Strategy, Simulation, Machine Tool Industry, Assembly Plant

\section{INTRODUCTION}

The machine tool industry, the focus of this paper, mostly produces large capital goods with unit prices of several hundred-thousand US dollars. Customers carefully consider the product specifications, functions, quality, prices, and delivery times before placing their orders. Advance rounds usually involve weeks or months of discussions and negotiations. This paper defines the orders under negotiation, but not yet confirmed, as potential orders (PO).

The production of machines is centred on assembly plants, also known as system plants. Due to the complex structure of the machines, assembly plants must spend significant time from weeks to months - processing and putting together the modules for the machines [1]. In order to shorten the lead time, some companies have shifted their production environments from make to order (MTO) and engineer to order (ETO) to make to stock (MTS) and configure to order (CTO) [2-6]. For example, the Anderson Group is one of the top-ranking producers of non-ferrous metal machine tools in Taiwan, and has adjusted the ratio of MTO/ETO to MTS/CTO from 9:1 to 2:8 through standardisation and modularisation, which has enabled assembly plants to shorten the lead time and enhance their flexibility in production planning.

The modules for each machine can be classified into general and critical types. Critical modules are more important and technical; thus, they are usually produced directly in assembly plants. In contrast, general modules can be outsourced. Therefore, it is essential for assembly plants to schedule the production of critical modules in order to avoid running out of stock or being unable to deliver machines on time. 
Orders might rush in once the demand for machines gathers momentum. During periods of high demand, unless customers have agreed to a long production lead time, assembly plants may not have sufficient capacity if they do not schedule production until after orders are confirmed [7-9]. This overcapacity schedule may lead to crowding-out orders, causing late production for certain orders and increased delay costs. Alternatively, during the early stages of demand growth, it is also possible for the assembly plant to suffer from idle capacity when many potential orders are still in negotiation and have yet to be confirmed.

When overloaded capacity happens, applying advanced capacity reservation to distribute capacity loading over time may be a strategy to relieve production congestion. Another possibility is to accept fewer orders - namely, to reduce the number of non-confirmed orders. This paper proposes the concept of "reservation threshold", which refers to immediately making production capacity reservations for orders once certain attributes of these orders reach a predetermined threshold, thereby enabling the prior production of critical modules and advance assembly in order to avoid the crowding-out effects from congested orders and the resulting delay penalties. Of course, these benefits must be balanced with the possibility of changed or cancelled orders after the prior production has occurred. This paper proposes three reservation strategies: module reservation, finished products reservation, and zero slack time with assembly reservation. The module reservation strategy refers to the reservation of the modules required for potential orders and beginning to schedule the assembly upon order confirmation. Similar to an MTS environment, the finished products reservation strategy requires the reservation of machines. When the required modules are ready, they are assembled to machines and await customers' orders. The zero slack time with assembly reservation strategy falls between the module reservation strategy and the finished products reservation strategy. Modules are reserved and assembly starts when order slack time falls to zero.

This research covers the interactions among customers, assembly plants, and general module suppliers, emphasising the production planning for assembly plants. For simplification, headquarters and assembly plants are viewed as one unit. Assembly plants may directly communicate with customers and gather order-related information during the communication (or negotiation) process. Orders are compared against the threshold value in order to determine whether assembly plants should plan a capacity reservation for these orders.

The rest of this paper is structured as follows. Section 2 provides a review of different production environments. The methodology, including system description and simulation model, is described in Section 3. Numerical experiments are illustrated in Section 4. A conclusion and further research directions are presented in Section 5.

\section{LITERATURE REVIEW}

This paper refers to the Anderson Group's production model centred on MTS/CTO. A survey is conducted on different production environments. As this paper intends to examine the capacity-planning issues associated with potential orders, the survey will also review the relevant literature regarding capacity planning, demand uncertainty, and capacity reservation. Finally, the system simulation serves as the tool to derive solutions. Supplementary information on the references for the tool in use will be provided.

MTS, CTO, MTO, and ETO are the four common production environments (models), and each has its own pros and cons. Many scholars have explored the selection and application of different production models. Shao and Dong [10] compared the effects of MTO and MTS production models on order fulfilment. Köber and Heinecke [11] conducted a case study on large agricultural machine producers and found that most large machine producers adopt the MTO model. However, if demand is unpredictable due to seasonality, the MTO approach's limited capacity reduces the flexibility in planning production and leads to difficulty in reacting 
to demand changes. Therefore, Köber and Heinecke [11] proposed a three-stage MTS production structure in response to seasonality demand.

Semini et al. [12] used a shipbuilding example to differentiate MTS/CTO/MTO/ETO based on the customer order decoupling point (CODP). They concluded that CODP positions upstream imply high levels of customisation whereas downstream positions allow short lead time and lower prices. Van Donk and van Doorne [4] investigated the effect of the location of the CODP on supply chain integration and found that MTO companies integrated with their suppliers by sharing forecast information and engaging in joint research and development (R\&D), that assemble-to-order (ATO) companies integrated with their suppliers by using information systems and planning, and that MTS companies integrated with their suppliers by intensively sharing forecast information. Beemsterboer et al. [13] explored the impact of demand fluctuation on utilisation and delivery delays when a company determined its product mix in MTO and MTS job shops. The results showed that the simple method of always giving priority to MTO items had better performance than other methods integrated with MTS items. Lu and Chen [14] studied a supplier and buyer supply chain and determined the decisions when the supplier should expand capacity under the MTO and MTS supply chains. The results indicated that, when the cost of capacity investment is small, total profits of MTS mechanism outperformed those of the MTO mechanism; moreover, when there is low uncertainty of customer orders, the total profits of the MTO mechanism outperformed those of the MTS mechanism. Goo et al. [15] studied a ship production scheduling problem, where shipbuilding belonged to an ETO manufacturing industry. They used a layer discrete event simulation to model layers of ship production and scheduling information, leading to simpler and easier to implement the proposed methodology in shipbuilding. Most existing literature examines the MTO/MTS hybrid production model [13, 14, 16-18]. In practice, the industry has been increasing the mix of CTO/MTS (e.g., Anderson Group) to shorten lead time and boost capacity utilisation in a market where demand fluctuates and customer needs are difficult to predict.

This paper constructs a model with the Arena simulation tool. Arena software is deployed to assist the model construction and analytical process. The process analyser (PAN) toolbox for Arena can be used to compare the results of multiple scenarios for adjusting key parameters. Because this study investigates the effect of the reservation threshold values of the module reservation strategy on total profits and the effect of the reservation threshold values of three reservation strategies on total profits, the PAN toolbox is used to compare the results in different scenarios. The detailed results will be discussed in Section 4.

\section{METHODOLOGY}

This section elaborates on the concerning system, problem description, and simulation model development.

\subsection{System and issue description}

This paper defines a total of six order statuses. As previously mentioned, potential orders (PO) are the orders currently under negotiation and likely to be confirmed in the future. When PO parameter (= probability of order transaction $\times$ hourly contribution) reaches the predetermined threshold of the assembly plant, capacity shall be reserved for the required modules or even machines to meet the expected demand. This type of potential orders is known as a prioritised potential order (PPO). Although a PPO has reached the reservation threshold, order transaction probability may still drop due to external factors, such as changes in the competitive business environment and customers' reduced purchase willingness. If PPO parameters fall below the reservation threshold during the negotiation process, it will be necessary to release the capacity reserved for the orders in question and return to the previous potential order status. Such orders 
are called resumed potential orders (RPO or PO'). If customers drop out of the negotiations and cancel the order, such orders are called cancelled orders (CCO). CCO can be transformed either from PO to $\mathrm{CCO}$ or from PO' to CCO. If customers drop out of the negotiations and cancel the PPO, such orders are called cancelled prioritised potential orders (CPPO). Finally, if orders are confirmed and the probability of order transaction is $100 \%$, such orders are called confirmed orders (CO). No new status is assigned to a cancelled PO or PO' because it does not affect the capacity changes.

This paper examines how assembly plants respond to PPOs for machines composed of critical modules. Under the module reservation strategy, which is the default strategy, these critical modules are manufactured by assembly plants, but they are only put together when the orders are confirmed. The early production of critical modules helps increase capacity utilisation and shorten lead time.

\subsection{Simulation model}

This paper first explores the scenario and constructs the simulation model by incorporating the module reservation strategy; the other two strategies examined are variations of this default strategy. The following relevant parameters and scenario setups are assumed:

(1) The inter-arrival time to start new negotiations for a new PO with customers follows an exponential distribution with $\lambda=5$ days.

(2) The initial value of transaction probability of a new PO follows a uniform distribution with the range of $[0,1]$.

(3) The changes to transaction probabilities for further negotiations follow a uniform distribution with the range of $[-1,1]$. If the cumulative probability of an order turns to a negative value after negotiations, the cumulative probability of the order is set to zero, and this order is deemed to being cancelled.

(4) The lead time for orders is known. The delivery time for each order starts from order confirmation, follows a uniform distribution with the range of [30, 45] days, and can be calculated in the unit of days. A penalty cost is added for late delivery.

(5) The demand of an order contains at least one machine. The number of each machine type of the order is known and follows a discrete uniform distribution with the range of $[0,3]$ machines. For example, one order can contain one machine of Type A, two machines of Type B, and no machines of Type C. As the unit price of machines is high, the demand for each order is usually low.

(6) An order cannot be divided into suborders, but delivery can be made in several batches. An order is not divisible because the capacity reservation is determined based on the entire order. However, delivery can occur in batches because the shipment of a portion of completed machines can be made in order to avoid overly long waiting times for customers, thereby reducing inventory costs and potential delay costs for assembly plants.

(7) Each negotiation occurs within a fixed time interval; however, the composition of the order does not change during the negotiation process.

(8) Given the research focus of internal capacity planning for assembly plants, this paper assumes that the aggregated capacity of multiple suppliers is normal (4 production lines) for the assembly plants. It is also assumed that suppliers are concentrated in locations close to the assembly plants in order to form a regional supply chain. Therefore, the lead time for procurement is not taken into consideration.

(9) The simulation assumes 500 new POs being generated per replication, with a total of 50 simulation replications performed. The simulation will be terminated when all POs depart the simulation model. Details will follow in the next section.

A potential order only starts to compete for production capacity when it becomes a PPO. To explore the crowding-out effect, the simulation time per run is the length between the first 
order's creation and the last order's departure from the simulation system. This study uses Arena to construct a simulation model. Fig. 1, as an example, represents the main flowchart of Type A machine under the module reservation strategy policy. The objective function is to maximise the total profits, which are calculated by adding total sales and subtracting the associated costs, including assembly costs, manufacturing costs, procurement costs, inventory costs (of machines, critical modules, and general modules), and delay costs.

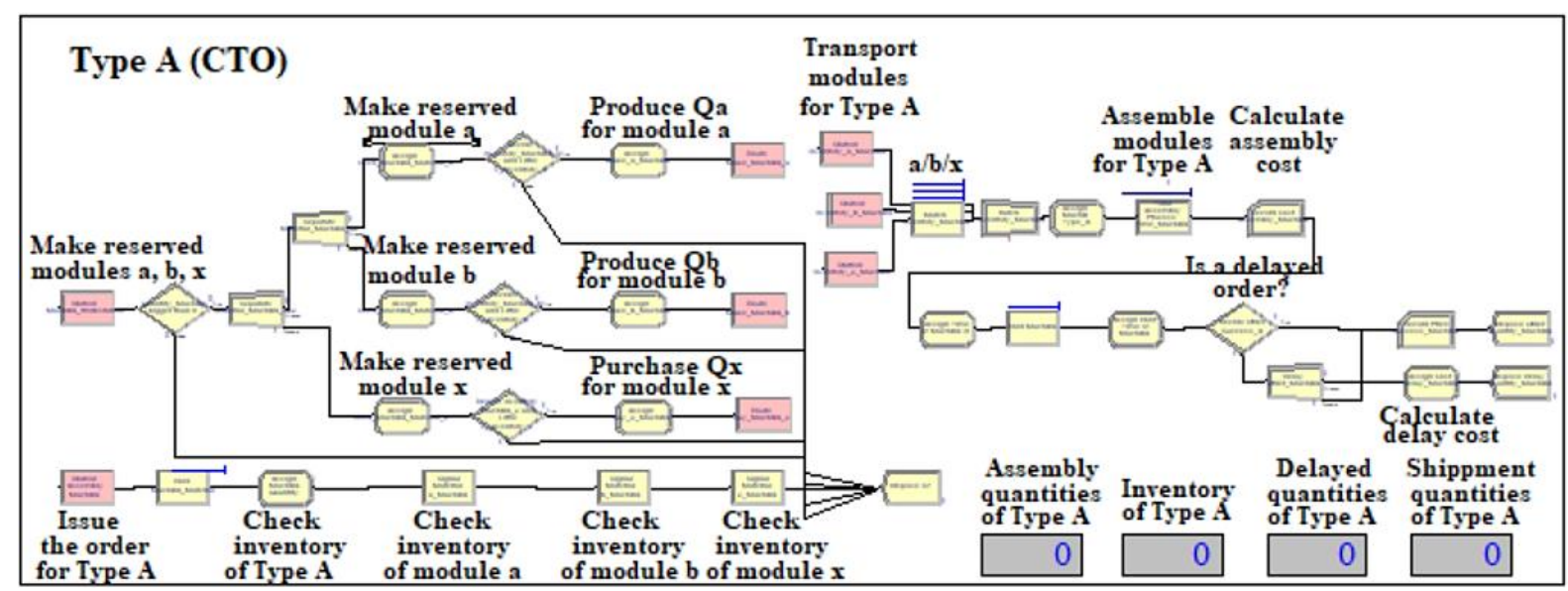

Figure 1: Flowchart of Type A machine under the module reservation strategy policy.

\section{RESULTS AND DISCUSSIONS}

This paper analyses the simulation statistics of the case company's computer numerical control (CNC) routers to demonstrate the importance of threshold setup for capacity reservations.

\subsection{Case description}

The case company is a machinery manufacturer and one of the major suppliers of woodworking machine tools in Asia. One of the company's key products is CNC routers, which include three function systems (modules): the feed system, the spindle system, and peripherals. Depending on the detailed specifications and customer requirements, $\mathrm{CNC}$ routers are classified as Type A, B, or C. Some of the modules for Type A and Type B CNC routers are mission critical; hence, product prices and inventory costs are relatively high. Therefore, Type A and Type B $\mathrm{CNC}$ routers are produced in the CTO model. In contrast, Type $\mathrm{C} \mathrm{CNC}$ routers are generic tools without critical technologies. The selling prices and inventory costs are relatively low due to the higher degree of specification standardisation. Thus, Type C CNC routers are produced in the MTS model. The Type A machine requires critical modules of $\mathbf{a}$ and $\mathbf{b}$ and a general module of $\mathbf{x}$. The Type B machine requires critical modules of $\mathbf{c}$ and $\mathbf{d}$ and a general module of $\mathbf{y}$. The Type $C$ machine requires general modules of $\mathbf{x}, \mathbf{y}$, and $\mathbf{z}$. The reference selling price of Types $\mathrm{A}, \mathrm{B}$, and C machines is 3,500,000 NT dollars, 3,000,000 NT dollars, and 2,000,000 NT dollars, respectively. The machine hourly contribution $(M H C)$ of Types $\mathrm{A}, \mathrm{B}$, and $\mathrm{C}$ machines is 13.9, 10.2 , and 5.7, respectively.

The Economic Production Quantity (EPQ) model can be used to estimate the production lot size $(Q)$. In addition, the restocking volume of general modules can be derived with the Economic Order Quantity (EOQ) model. Symbol $s$ represents the level of safety stock. For Types $\mathrm{A}$ and $\mathrm{B}$, the $(s, Q)$ of critical modules (i.e., $\mathbf{a}, \mathbf{b}, \mathbf{c}$, and $\mathbf{d})$ is set to $(5,10)$ while the $(s$, $Q$ ) of general modules (i.e., $\mathbf{x}, \mathbf{y}$, and $\mathbf{z})$ is set to $(5,10)$. As Types A and $\mathrm{B}$ are produced in the CTO model, there is no inventory in advance. Hence, there is no $(s, Q)$ of Types $\mathrm{A}$ and $\mathrm{B}$. However, Type $\mathrm{C}$ is produced in the MTS model, resulting in an existing $(s, Q)$ inventory of Type $\mathrm{C}$ machine, and the $(s, Q)$ is set to $(4,8)$. 


\subsection{Role of thresholds}

This paper seeks to justify the valuable role of threshold, particularly when capacity is insufficient. The dispatching rule is first come first served (FCFS). The PAN toolbox of Arena software is applied to solve the "what-if" scenario with the gradual increment of threshold values. The corresponding objective function values (i.e., total profits and related costs) are recorded for different threshold values. The experiment produces 50 simulation replications for each given threshold value. The obtained results are exported into Excel spreadsheets and plotted onto a graph presenting the effects of threshold value changes to corresponding total profits.

This paper defines the threshold as the multiplication of an order's hourly contribution and transaction probability. The Type A machine reports the highest $M H C$ of 13.9. As transaction probabilities range between 0 and 1, the threshold value must fall within the range of 0 and 13.9. If each increment to the threshold value is 0.1 , a total of 140 data entries (from 0 to 13.9) can be established to plot the curve between threshold values and total profits.

Table I: Cost analysis of the reservation strategy versus the no-reservation strategy in different production line scenarios.

\begin{tabular}{|c|c|c|c|c|c|c|c|c|c|}
\hline \multicolumn{10}{|c|}{ No-reservation strategy } \\
\hline $\begin{array}{l}\text { PD } \\
\text { lines }\end{array}$ & $\begin{array}{c}\mathrm{TH} \\
\text { value }\end{array}$ & $\begin{array}{c}\text { Total } \\
\text { profits }\end{array}$ & $\begin{array}{l}\text { Total } \\
\text { sales }\end{array}$ & $\begin{array}{c}\text { AS } \\
\text { costs }\end{array}$ & $\begin{array}{l}\text { PR } \\
\text { costs }\end{array}$ & $\begin{array}{c}\mathrm{DE} \\
\text { costs }\end{array}$ & $\begin{array}{l}\text { IN cost for } \\
\text { machines } \\
\text { assembled }\end{array}$ & $\begin{array}{l}\text { IN cost for } \\
\text { general and } \\
\text { critical } \\
\text { modules }\end{array}$ & MA costs \\
\hline 2 & - & $-192,286$ & 249,395 & 65,108 & 62,141 & 248,832 & 762 & 8,830 & 56,008 \\
\hline 3 & - & $\begin{array}{l}-59,768 \\
\end{array}$ & 247,535 & 64,521 & 62,142 & 119,926 & 522 & 4,809 & 55,383 \\
\hline 4 & - & 4,738 & 246,126 & 64,204 & 61,971 & 56,931 & 371 & 2,855 & 55,056 \\
\hline 5 & - & 43,450 & 244,648 & 63,787 & 61,554 & 19,215 & 311 & 1,771 & 54,560 \\
\hline 6 & - & 58,130 & 245,716 & 64,111 & 61,962 & 4,850 & 341 & 1,625 & 54,697 \\
\hline \multicolumn{10}{|c|}{ Reservation strategy } \\
\hline $\begin{array}{l}\text { PD } \\
\text { lines }\end{array}$ & $\begin{array}{c}\mathrm{TH} \\
\text { value }\end{array}$ & $\begin{array}{c}\text { Total } \\
\text { profits }\end{array}$ & $\begin{array}{l}\text { Total } \\
\text { sales }\end{array}$ & $\begin{array}{c}\mathrm{AS} \\
\text { costs }\end{array}$ & $\begin{array}{c}\text { PR } \\
\text { costs }\end{array}$ & $\begin{array}{c}\mathrm{DE} \\
\text { costs }\end{array}$ & $\begin{array}{l}\text { IN cost for } \\
\text { machines } \\
\text { assembled }\end{array}$ & $\begin{array}{l}\text { IN cost for } \\
\text { general and } \\
\text { critical } \\
\text { modules }\end{array}$ & MA costs \\
\hline 2 & 1.3 & $-52,713$ & 242,495 & 63,401 & 61,116 & 109,492 & 756 & 5,530 & 54,913 \\
\hline 3 & 6.9 & 48,632 & 243,320 & 63,445 & 61,990 & 10,597 & 816 & 3,343 & 54,497 \\
\hline 4 & 8.7 & 57,638 & 243,751 & 63,551 & 62,281 & 804 & 1,169 & 3,895 & 54,413 \\
\hline 5 & 6.2 & 58,168 & 244,312 & 63,628 & 62,183 & 76 & 1,630 & 4,555 & 54,072 \\
\hline 6 & 4.8 & 57,967 & 244,952 & 63,826 & 62,443 & 12 & 1,894 & 4,853 & 53,957 \\
\hline
\end{tabular}

Note 1: the monetary unit is 10,000 NT dollars. Note 2: PD: Production, TH: Threshold,

AS: Assembly, PR: Procurement, DE: Delay, IN: Inventory, and MA: Manufacturing.

Table I shows that, with two to five production lines, the total profits of the reservation strategy with the optimal threshold value outperformed those of the no-reservation strategy. Based on the cost analysis, the results show that the reservation strategy had lower delay costs than the no-reservation strategy, but that the reservation strategy had higher inventory costs for machines assembled than the no-reservation strategy. The reason was that the reservation strategy made a reservation for general and critical modules for the customer's order when it passed the predetermined threshold, where the order became a PPO. Then the manufacturer prepared the required number of the general and critical modules for the customer's order before it was confirmed. Therefore, the manufacturer could reduce production lead time by manufacturing critical modules and purchasing the general module much earlier, leading to a significant reduction in delay costs and a slight increase in inventory cost for the machines assembled. 
When there are two or three production lines, namely insufficient production capacity, the manufacturer could use the reservation strategy for the short- or medium-term capacity planning to save delay costs and increase total profits instead of increasing production capacity. Usually, machinery manufacturers require a long lead time to increase their production capacity, but customer demand fluctuates quickly. When customer demand exceeds current production capacity, the reservation strategy is recommended. This is the rationale behind this study.

\subsection{Analysis of scenario changes: Negotiation probability distribution changes}

If a PO emerges, the salesperson in charge starts to negotiate with a new customer. This study defines the transaction probability as two values: PO negotiation probability and PPO negotiation probability. Based on the simulation model assumptions, this paper initially assumes that both the PO negotiation probability and PPO negotiation probability meet a uniform $[-1,1]$ distribution.

In this section, this study relaxes this assumption and explores the impacts of different negotiation probabilities (i.e., a fixed PO negotiation probability distribution with different PPO negotiation probability distributions and a fixed PPO negotiation probability distribution with different $\mathrm{PO}$ negotiation probability distributions) on total profits by changing threshold values. The reason for performing the sensitivity analysis for different negotiation probabilities of PO and PPO is because the salespeople and customers may change their attitudes or marketing/purchasing strategies during the entire negotiation process. Figs. 2, 3, and 4 represent a fixed PO negotiation probability distribution, with uniform [-0.3, 0.4] distribution, uniform $[-0.3,0.7]$ distribution, and uniform $[-0.3,1.0]$ distribution, respectively, and five different PPO negotiation probability distributions.

Fig. 2 leads to the following observations:

(1) When the PPO negotiation probability distribution range increases from a uniform $[-0.2,0.2]$ distribution to a uniform $[-1.0,1.0]$ distribution, the curve shifts from the left to right side. Thus, under the same threshold value, the smaller the PPO negotiation probability distribution range is, the larger the total profits will be because the larger PPO negotiation probability distribution range results in having a greater chance to transform a PPO to a CPPO or PO'. Conversely, the smaller PPO negotiation probability distribution range results in having a smaller chance to transform a PPO to a CPPO or PO', thereby leading to a greater chance to transform a PPO to a CO. Hence, the smaller PPO negotiation probability distribution range has more confirmed orders, generating higher total profits.

(2) For each curve, when the threshold value increases from 3 to 10, total profits increase; when the threshold value increases from 10 to 13.9, total profits remain almost unchanged.

Fig. 3 leads to similar observations as those from Fig. 2:

(1) When the PPO negotiation probability distribution range increases from a uniform $[-0.2,0.2]$ distribution to a uniform $[-1.0,1.0]$ distribution, the curve shifts from the left to right side.

(2) Because Fig. 3 (uniform [-0.3, 0.7]) has a larger PO negotiation probability distribution range on the positive side than Fig. 2 (uniform $[-0.3,0.4]$ ), the maximal total profits in Fig. 3 are larger than those in Fig. 2 as the larger PO negotiation probability distribution yields more confirmed orders, thereby generating more total sales and total profits.

(3) For each curve, when the threshold value increases from 2 to 9, total profits increase; when the threshold value increases from 9 to 13.9, total profits remain almost unchanged.

Fig. 4 leads to the following observations:

(1) When the PPO negotiation probability distribution range increases from a uniform $[-0.2,0.2]$ distribution to a uniform $[-1.0,1.0]$ distribution, the curve shifts from the left side to the right side. Furthermore, the threshold value of the maximal total profits of each curve in Fig. 4 is less than 6. 
(2) Based on the results of Figs. 3 and 4, although the larger PPO negotiation probability distribution range results in having a greater chance to transform a PPO to a CO, the maximal value of total profits (about 135.5 million NT dollars) in Fig. 4 is less than that value (about 136 million NT dollars) in Fig. 3 because too many confirmed orders generate an overcapacity schedule, thereby generating the crowding-out effect. This will lead to a higher delay cost, thereby resulting in the reduction of total profits.

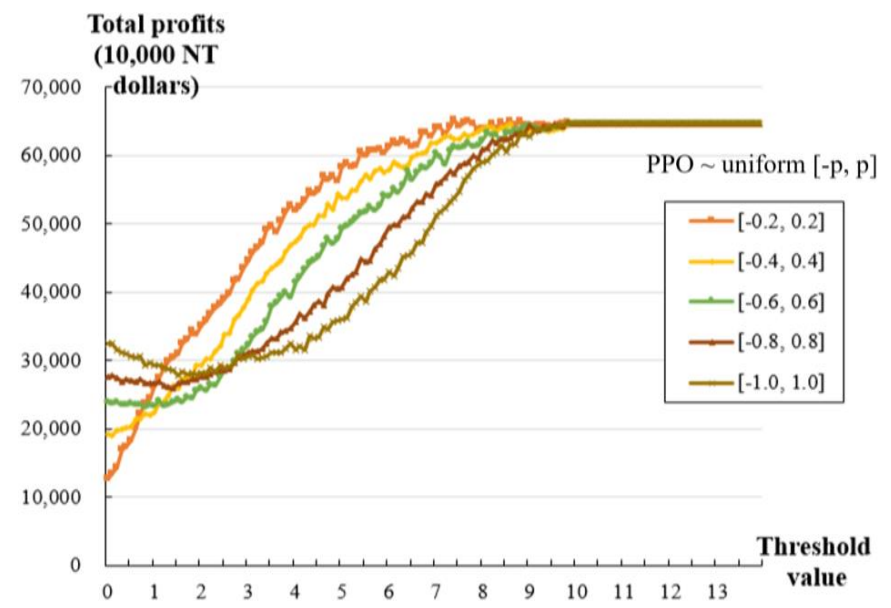

Figure 2: The impact on adjustment of PPO negotiation probability distributions with a fixed PO's uniform $[-0.3,0.4]$ distribution.

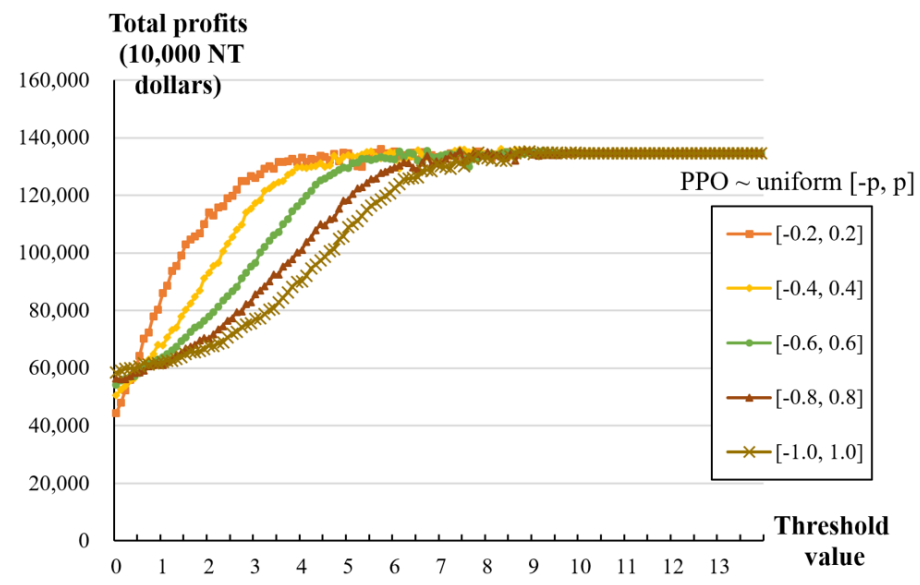

Figure 3: The impact on adjustment of PPO probability distributions with a fixed PO's uniform $[-0.3,0.7]$ distribution.

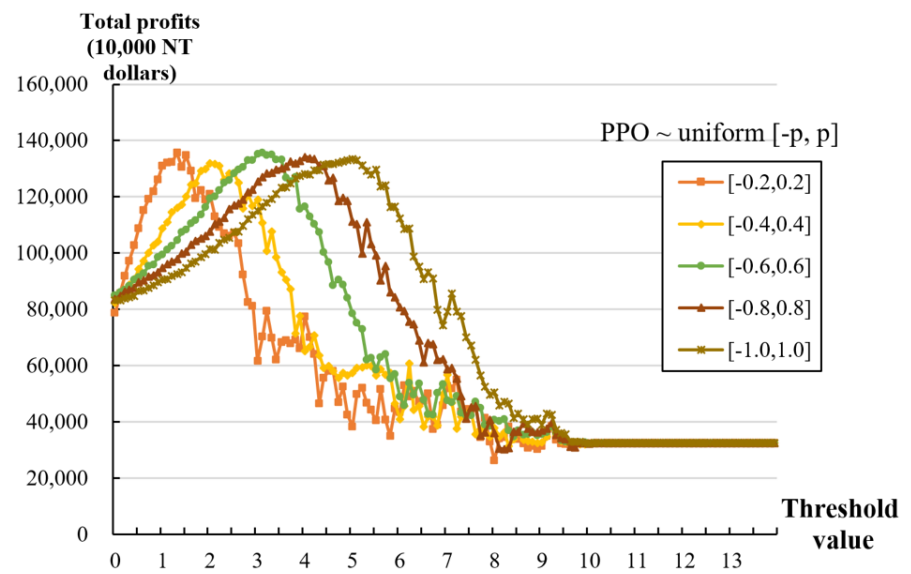

Figure 4: The impact on adjustment of PPO negotiation probability distributions with a fixed PO's uniform $[-0.3,1.0]$ distribution. 


\subsection{Analysis of scenario changes: Three reservation strategies}

Before this section, all the simulation scenarios adopted the module reservation strategy; however, two other reservation strategies are considered as well. This paper first explains the details of these three strategies before presenting their possible effects. As Types A and B machines are CTO machines, the start time of their assembly process depends on the reservation strategies. Type C machines (i.e., MTS machines) are assembled in advance, are independent of reservation strategies, and are stored as the inventory for shipment.

(1) Module reservation (MR): This refers to early preparation for the required module, including the production of critical modules. Assembly for Types A and B machines (i.e., CTO machines) only begins upon order confirmation.

(2) Finished products reservation (FPR): As the name suggests, this strategy involves the reservation of finished machines. Assembly for Types A and B machines (i.e., CTO machines) starts as soon as the modules are ready and the finished machines are kept in the warehouse. Compared to the MR strategy, this strategy shortens the lead time. However, this strategy risks increased finished product inventory costs and potential liquidity discounts, if orders are unexpectedly cancelled.

(3) Zero slack time with assembly reservation (ZSTAR): This strategy falls between MR and FPR. As soon as the production slack time for Types A and B machines (i.e., CTO machines) falls to zero, the modules previously reserved for PPOs are immediately assembled into finished products, regardless of whether the concerned PPO has turned into the CO.

This paper analyses the simulation results of three reservation strategies and explores their relationships between threshold values and total profits. Fig. 5 shows that, for the threshold value between 0 and 10, the MR strategy has the maximal total profits, followed by the ZSTAR strategy and FPR strategy. When the threshold value increases from 0 to 10, total profits of the MR strategy increase very slightly, but total profits of the FPR strategy and ZSTAR strategy increase in an upward trend. When the threshold value increases from 10 to 13.9, total profits of the FPR strategy and ZSTAR strategy remain almost unchanged.

Fig. 6 shows the cost analysis of the FPR strategy by varying threshold values. In Fig. 6, when the threshold value increases from 0 to 10 , total profits show a positive increasing trend because smaller threshold values of the FPR strategy let the case assembly plant make more reservations for customers' orders, thereby leading to increments in assembly, procurement, and manufacturing costs. Therefore, when increasing threshold values of the FPR strategy, the case assembly plant becomes more conservative to make reservations for customers' orders, thereby leading to increases in total profits.

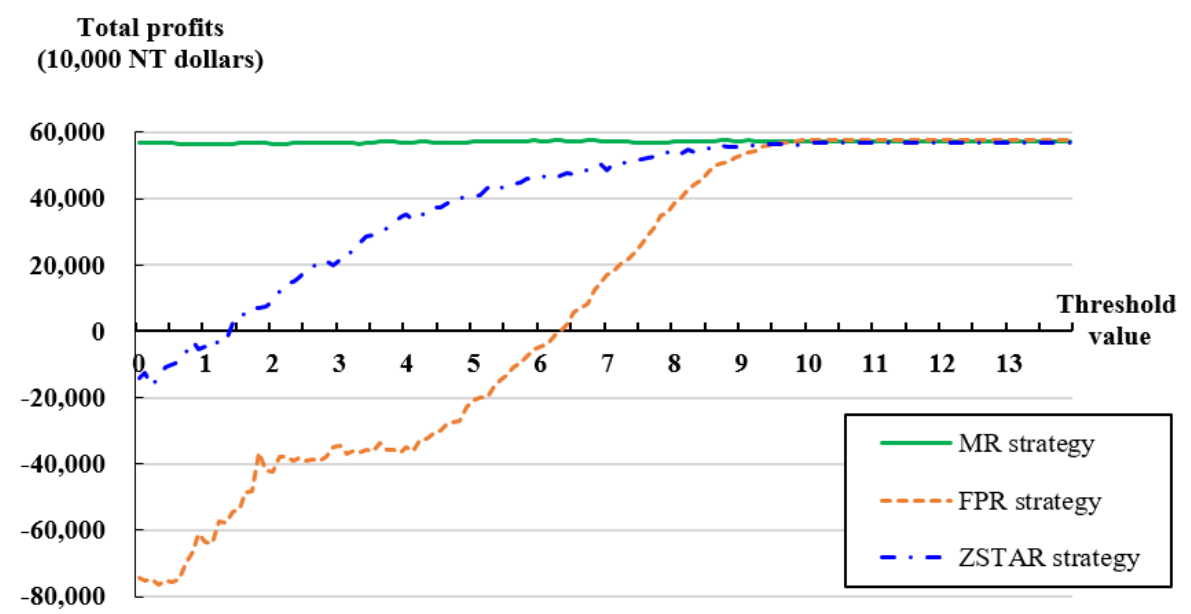

Figure 5: The impact of the three reservation strategies with a fixed PO's uniform [-1.0, 1.0] distribution and a fixed PPO's uniform $[-1.0,1.0]$ distribution. 


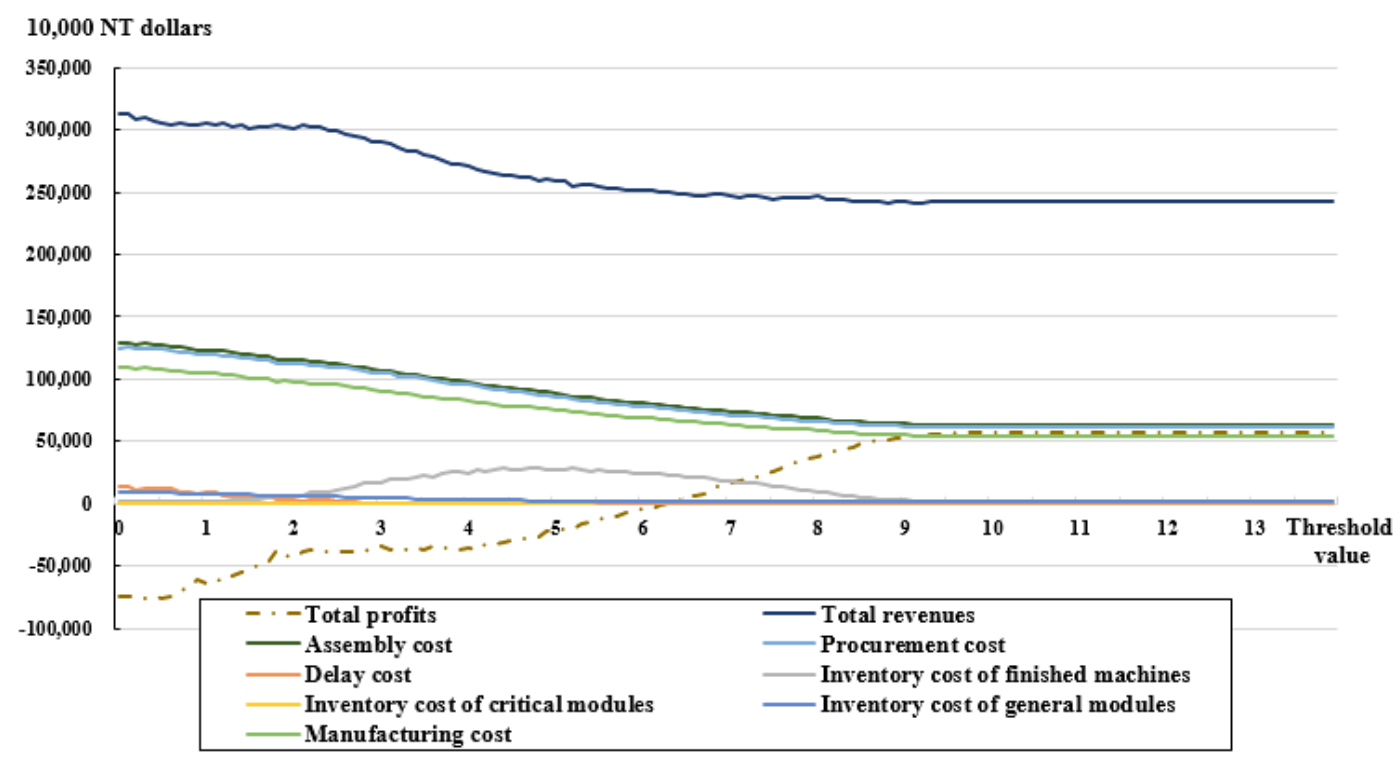

Figure 6: The cost analysis of the FPR strategy by varying threshold values.

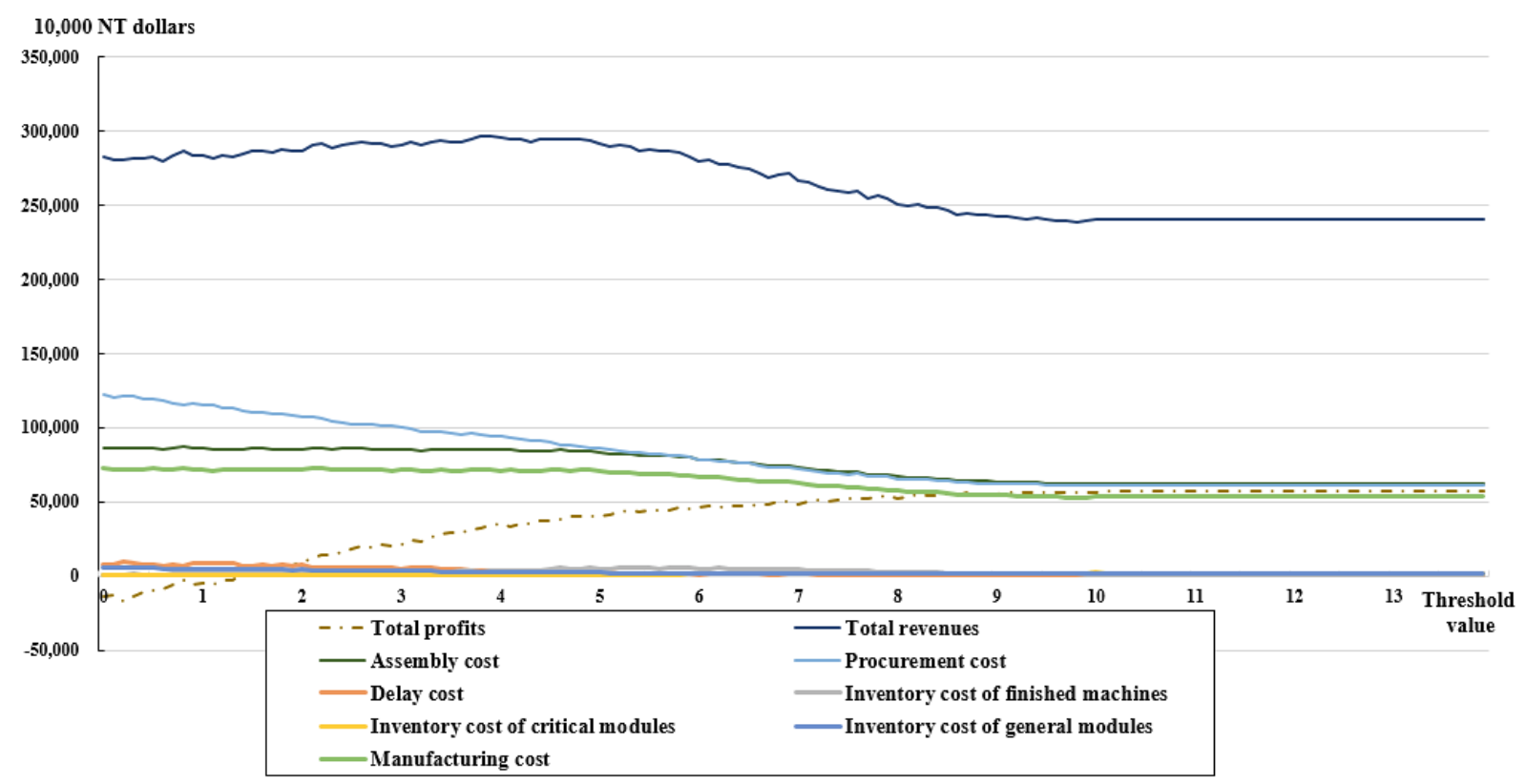

Figure 7: The cost analysis of the ZSTAR strategy by varying threshold values.

Similar to the observations of the FPR strategy, Fig. 7 shows the cost analysis of the ZSTAR strategy by varying threshold values. In Fig. 7, when the threshold value increases from 0 to 10, total profits show a positive increasing trend. Compared to Figs. 6 and 7, when the threshold value falls within the range of 0 to 9.7, the inventory cost of finished machines of the FPR strategy is larger than that of the ZSTAR strategy because the ZSTAR strategy helps the assembly plant postpone the starting time to assemble the machines as late as possible.

\section{CONCLUSION}

This study has examined the machine tool industry to construct a simulation model for an MTS/CTO hybrid production mode. Statistical data from a case company were used in the simulation runs. The results indicated that setting up the reservation threshold is a valuable tool for companies to pursue maximal total profits when capacity is fixed and the quantity of orders increases, as early preparations can mitigate the order crowding-out effect. 
This research refers to normal capacity (4 production lines) as the basic scenario and adjusts the parameters (i.e., negotiation probability distributions) for the MR strategy. Furthermore, this study adjusts the PO's and PPO's negotiation probability distributions for the three reservation strategies in order to analyse the effects on reservation threshold values in different scenarios. Ultimately, this paper has described the commonly seen practical problems associated with the impact of reservation thresholds on total profits from potential orders in a tangible and sensible manner and has constructed a simulation model accordingly. Simulations were run using real-life statistics, and conclusions have been drawn based on the simulation results. Although the model is not applicable to all industries, the research findings backed by factual statistics and graphs can serve as a reference for decision makers working in sectors with similar characteristics to the machinery (machine tool) industry, meaning they no longer have to rely on just rules of thumb.

This study has explored the effects of threshold values on potential orders, and the research was designed for the production planning of a single assembly plant. Future studies should expand the research scope by incorporating suppliers' locations and capacity into the model and extending the research topics into supply chain management. Another suggestion is to consider transportation issues, as the threshold value might be subject to the impact of transportation time and distance, and the results may differ. Examining customers' behaviour by analysing customer information and then defining the interaction between order transaction probabilities and customers' behaviour in the simulation model would also be fruitful areas for further study. This approach may allow setting threshold values to reflect reality more accurately, as companies can boost total profits with marketing techniques. Furthermore, it is possible to identify the interdependence between order changes and outsourcing ratios. The more volatile the order levels (e.g., products on season or off season), the more outsourcing may occur. In such instances, it may be advisable to expand the list of suppliers to cope with drastic changes in order to leverage demands among suppliers rather than by resorting solely to capacity expansion.

\section{ACKNOWLEDGEMENTS}

This work was partially supported by Chang Gung Memorial Hospital under Grant BMRPE93.

\section{REFERENCES}

[1] Yang, S. L.; Xu, Z. G.; Wang, J. Y. (2019). Modelling and production configuration optimization for an assembly shop, International Journal of Simulation Modelling, Vol. 18, No. 2, 366-377, doi:10.2507/IJSIMM18(2)CO10

[2] Hutter, T.; Haeussler, S.; Missbauer, H. (2018). Successful implementation of an order release mechanism based on workload control: A case study of a make-to-stock manufacturer, International Journal of Production Research, Vol. 56, No. 4, 1565-1580, doi:10.1080/ $\underline{00207543.2017 .1369598}$

[3] Zeppetella, L.; Gebennini, E.; Grassi, A.; Rimini, B. (2017). Optimal production scheduling with customer-driven demand substitution, International Journal of Production Research, Vol. 55, No. 6, 1692-1706, doi: $10.1080 / 00207543.2016 .1223895$

[4] Van Donk, D. P.; van Doorne, R. (2016). The impact of the customer order decoupling point on type and level of supply chain integration, International Journal of Production Research, Vol. 54, No. 9, 2572-2584, doi: $10.1080 / 00207543.2015 .1101176$

[5] Yang, B.; Chen, W.; Lin, C. (2017). The algorithm and simulation of multi-objective sequence and balancing problem for mixed mode assembly line, International Journal of Simulation Modelling, Vol. 16, No. 2, 357-367, doi:10.2507/IJSIMM16(2)CO10

[6] Li, Q. Z.; Fan, X. W.; Huang, W. J.; Kwangseek, C. (2017). Collaborative supply model and case simulation in a two-level assemble-to-order system in the context of global purchasing, 
International Journal of Simulation Modelling, Vol. 16, No. 3, 471-483, doi:10.2507/ IJSIMM16(3)9.393

[7] Mishra, B. K.; Prasad, A.; Srinivasan, D.; ElHafsi, M. (2017). Pricing and capacity planning for product-line expansion and reduction, International Journal of Production Research, Vol. 55, No. 18, 5502-5519, doi: $10.1080 / 00207543.2017 .1323132$

[8] Melchiors, P.; Leus, R.; Creemers, S.; Kolisch, R. (2018). Dynamic order acceptance and capacity planning in a stochastic multi-project environment with a bottleneck resource, International Journal of Production Research, Vol. 56, No. 1-2, 459-475, doi:10.1080/00207543.2018.1431417

[9] Moon, S.; Ji, W.; Moon, H.; Kim, D. (2018). A simulation of order resonance phenomenon in a supply chain triggered by reinforcing loop, International Journal of Simulation Modelling, Vol. 17, No. 2, 231-244, doi:10.2507/IJSIMM17(2)421

[10] Shao, X.-F.; Dong, M. (2012). Comparison of order-fulfilment performance in MTO and MTS systems with an inventory cost budget constraint, International Journal of Production Research, Vol. 50, No. 7, 1917-1931, doi:10.1080/00207543.2011.562562

[11] Köber, J.; Heinecke, G. (2012). Hybrid production strategy between make-to-order and make-tostock: A case study at a manufacturer of agricultural machinery with volatile and seasonal demand, Procedia CIRP, Vol. 3, 453-458, doi:10.1016/j.procir.2012.07.078

[12] Semini, M.; Haartveit, D. E. G.; Alfnes, E.; Arica, E.; Brett, P. O.; Strandhagen, J. O. (2014). Strategies for customized shipbuilding with different customer order decoupling points, Proceedings of the Institution of Mechanical Engineers, Part M: Journal of Engineering for the Maritime Environment, Vol. 228, No. 4, 362-372, doi:10.1177/1475090213493770

[13] Beemsterboer, B.; Land, M.; Teunter, R.; Bokhorst, J. (2017). Integrating make-to-order and maketo-stock in job shop control, International Journal of Production Economics, Vol. 185, 1-10, doi:10.1016/j.ijpe.2016.12.015

[14] Lu, Q. H.; Chen, X. F. (2018). Capacity expansion investment of supplier under make-to-order and make-to-stock supply chains, International Journal of Production Economics, Vol. 198, 133-148, doi:10.1016/j.ijpe.2018.01.009

[15] Goo, B.; Chung, H.; Han, S. (2019). Layered discrete event system specification for a ship production scheduling model, Simulation Modelling Practice and Theory, Vol. 96, Paper 101934, 13 pages, doi:10.1016/j.simpat.2019.101934

[16] Renna, P. (2016). Production control policies for a multistage serial system under MTO-MTS production environment, International Journal of Advanced Manufacturing Technology, Vol. 83, No. 1-4, 449-459, doi: $10.1007 / \mathrm{s} 00170-015-7587-\mathrm{z}$

[17] Beemsterboer, B.; Land, M.; Teunter, R. (2016). Hybrid MTO-MTS production planning: An explorative study, European Journal of Operational Research, Vol. 248, No. 2, 453-461, doi:10.1016/j.ejor.2015.07.037

[18] Wang, Z.; Qi, Y. Q.; Cui, H. R.; Zhang, J. H. (2019). A hybrid algorithm for order acceptance and scheduling problem in make-to-stock/make-to-order industries, Computers \& Industrial Engineering, Vol. 127, 841-852, doi:10.1016/j.cie.2018.11.021 